\title{
Improving the mechanical properties of zirconia in instrument bearings
}

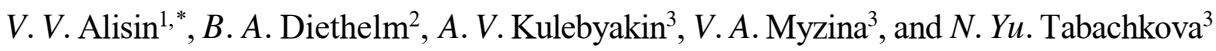 \\ ${ }^{1}$ Mechanical Engineering Research Institute of the Russian Academy of Sciences, 119334, 4 Bardina \\ st, Moscow, Russia \\ ${ }^{2}$ Diethelm Research, 8001, Hornbachstrasse 50, Zurich, Switzerland \\ ${ }^{3}$ Prokhorov General Physics Institute of the Russian Academy of Sciences, 119991, 38 Vavilov st, \\ Moscow, Russia
}

\begin{abstract}
The article presents the issues of replacing leucosapphires in jeweled bearings of the axes of precision instruments with nanostructured crystals of partially stabilized zirconia. The statement is substantiated that doping with rare earth elements provides an improvement in the performance properties of precision instruments by improving the mechanical properties of bearing materials. The efficiency of doping of zirconia crystals with cerium and neodymium oxides is studied. It was found that doped crystals have increased plasticity, which provides an increase in the crack resistance of crystals. Special attention is paid to the issues of increasing the survivability of high-speed rotor bearings by replacing the thrust bearing of leucosapphire with nanostructured crystals of partially stabilized zirconia doped with cerium and neodymium. The efficiency of improving the mechanical properties is confirmed by the X-ray phase analysis of crystals. The phase composition is studied by Raman scattering and the lattice parameters are determined. The increased crack resistance of the thrust bearing is confirmed by tests performed using the kinetic microhardness method.
\end{abstract}

\section{Introduction}

Machines and instruments with high-speed vertical rotors are common in various industries. They are used in spinning devices of weaving machines, gyroscopic instruments, centrifugal separators for separating liquid and gaseous mixtures in the food and chemical industries. Studies of cellular and molecular biology are widely applies method of studying dispersed media in the mode of analyzing the elements of the dispersed phase by light scattering and fluorescence signals, based on the use of ultracentrifuges [1]. Beckman Coulter manufactures commercial ultracentrifuges up to $150,000 \mathrm{rpm}$ (Optima MAX-XP). The reliability and service life of such machines depend on the tribological properties of the support bearing materials.

\footnotetext{
* Corresponding author: vva-imash@yandex.ru
} 
Traditionally, frictional assemblies of precision mechanisms are made with jeweled bearings, as a rule, these are transparent corundum, such as rubies, leucosapphires. The feature of the bearings design is that they represent a small-sized high-speed rolling bearing, the ultimate bearing capacity of which is determined by the crack resistance of the crystal from which the thrust bearing is made. Combinations of hard coatings [2] and various lubricants [3] are used to improve the tribological properties of rotor bearings. The paper [4] studies tribological behavior of an amorphous carbon nitride coating under dry sliding friction. A comparison is made with the tribological properties of sapphire.

A strong effect of the environment on the tribological characteristics of the friction pair is noted. The nonlinear dynamic behavior of a rigid rotor interacting with different types of support bearings has been studied [5]. The stability of the rotor at high speeds is considered in paper [6]. The paper [7] studies the possibility of adjusting the rotor bearings.

One of the most important requirements for the material of thrust bearing is high parameters of crack resistance and good tribotechnical characteristics. Partially stabilized zirconia (PSZ) crystals, which are solid solutions of zirconium dioxide with yttrium oxide (in the range of yttrium oxide concentrations from 2 to 4 mol.\%), have the highest crack resistance and the best antifriction properties of all technical crystals and ceramics. When comparing the main mechanical characteristics of PSZ crystals with sapphire and zirconium ceramics of similar composition, the advantages of PSZ crystals are based on their higher crack resistance and bending strength.

The practice of mechanical processing of PSZ crystals has shown that when forming the edges of products, chips occur due to the low plasticity of the crystals, which is an unacceptable defect. Therefore, for the practical using of PSZ crystals, it is necessary to improve the edge strength, both by increasing the plasticity of the crystal and by strengthening the edges, for example, using laser treatment. An effective way of improving the mechanical characteristics of PSZ crystals is the introduction of impurities of rare-earth and transition elements into the crystal matrix [8] and selection of optimal synthesis conditions [9]. Optimization of the composition of PSZ crystals by doping with additional impurities of rare-earth and transition elements will increase crack resistance, wear resistance and plasticity of the centrifuge bearing material, which gives reason to expect an increase in the bearing capacity of the bearing and its service life in devices with an increased rotor speed in comparison with production samples made from leucosapphire. Physical methods of surface examination are widely used to study the nature of surface wear [8-10]. Tribological studies of vertical rotor bearings with thrust bearings made of zirconia crystals are extremely insufficient.

The aim of the work is to select and optimize the compositions of the PSZ crystals according to their mechanical characteristics, to study the effect on them of the synthesis technology and the processing technology of the material intended for the manufacture of vertical rotor bearings.

\section{Materials and methods}

The subject of the study was nanostructured partially stabilized zirconia crystals micro alloyed with rare-earth elements. A series of PSZ crystals with an yttrium oxide content from 2.0 to $3.7 \mathrm{~mol}$.\% was synthesized, as well as additionally doped with cerium, neodymium and cobalt oxides. Crystals were grown using method of directional melt crystallization in a cold container using direct high-frequency heating. The diameter of the cold container was $130 \mathrm{~mm}$, the growth rate varied from 3 to $20 \mathrm{~mm} / \mathrm{h}$, and the operating atmosphere was air. As starting materials, we used oxides of zirconium, yttrium, cerium, neodymium and cobalt of the "HPM" (highly purified material) grade. The weight of the material loaded into the cold container was $5-6 \mathrm{~kg}$. 
Tests on a kinetic microhardness tester were performed in accordance with the international standard ISO/DIS 14577-1:2002. As an indenter it was used a diamond tetrahedral Vickers pyramid with a complete angle of $136^{\circ}$ at the top of the indenter. Samples for research were made from PSZ crystals in the form of plane-parallel plates with dimensions of $10 \times 10 \times 4 \mathrm{~mm}^{3}$ with one polished surface. The measurements were performed under the following conditions: load range is $1-10 \mathrm{~N}$, loading and unloading speed is $2 \mathrm{~N} / \mathrm{min}$, and pause is $3 \mathrm{sec}$. The test method makes it possible to correctly determine the characteristics of the material in a wide range of loads, taking into account the deviations of the indenter geometry from the ideal shape, the elastic deflection of the surface in the contact area, the rigidity of the power circuit of the instrument, drifts, as well as a number of other factors influencing the measurement results.

The phase composition of the synthesized crystals was studied by X-ray phase analysis and Raman scattering method. The internal structure was examined using transmission electronic microscopy.

\section{Results and discussion}

The main cope of the experiments were performed on crystals, the composition of which is presented in Table 1. Some of the studies were performed on crystals with the $\mathrm{ZrO}_{2}$ composition of $2.8 \mathrm{~mol} . \% \mathrm{Y}_{2} \mathrm{O}_{3}$. The crystals had a columnar shape with a height of $30-50$ $\mathrm{mm}$, the width varied from 10 to $20 \mathrm{~mm}$. There were no visible defects and cracks on the crystal surface.

Table 1. Composition of the synthesized crystals of zirconium dioxide

\begin{tabular}{|c|c|c|c|}
\hline \multirow{2}{*}{ Sample No. } & \multicolumn{3}{|c|}{ Composition } \\
\cline { 2 - 4 } & $\mathrm{Y}_{2} \mathrm{O}_{3}, \mathbf{m o l} . \%$ & $\mathrm{Ce}_{2} \mathrm{O}_{3}, \mathbf{m o l} . \%$ & $\mathrm{Nd}_{2} \mathrm{O}_{3}, \mathbf{m o l} . \%$ \\
\hline 1 & 2,141 & 0,436 & 0,223 \\
\hline 2 & 2,036 & 0,653 & 0,111 \\
\hline 3 & 2,5 & 0,17 & 0,13 \\
\hline 4 & 2,5 & 0,2 & 0,1 \\
\hline 5 & 2,5 & 0,256 & 0,044 \\
\hline 6 & 2,031 & 0,435 & 0,334 \\
\hline
\end{tabular}

At a growth rate of $3 \mathrm{~mm} / \mathrm{h}$, the crystals were large, but some began to crack due to the thermal stresses arising during the growth process. An increase in the growth rate to $20 \mathrm{~mm} / \mathrm{h}$ led to a decrease in the size of crystals and a less uniform distribution of impurities along the growth axis. The most optimal growth rate was $10 \mathrm{~mm} / \mathrm{h}$.

Investigations of the phase composition with method of Raman scattering showed that at a growth rate of $10 \mathrm{~mm} / \mathrm{h}$ the samples have a homogeneous tetragonal structure along the entire length from the beginning to the end of crystal growth (Fig. 1). 


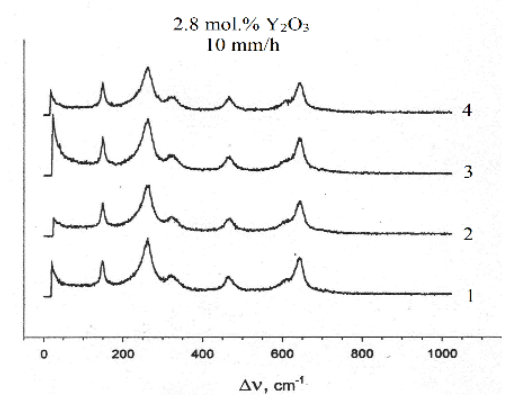

Fig. 1. Raman scattering spectra of the $\mathrm{ZrO}_{2}-2.8$ mol.\% $\mathrm{Y}_{2} \mathrm{O}_{3}$ sample, taken at 4 points along the crystal length

In addition, an analysis of the Raman scattering spectra shows that additional doping does not have a significant effect on the phase composition of the crystals; it remains tetragonal (Fig. 2).

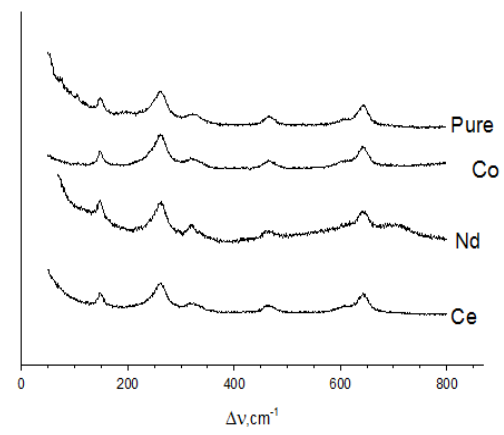

Fig. 2. Raman scattering spectra of PSZ crystals with the $\mathrm{ZrO}_{2}-2.8$ mol.\% $\mathrm{Y}_{2} \mathrm{O}_{3}$ doped with $\mathrm{Co}, \mathrm{Ce}$ and Nd impurities

The study of the phase composition by X-ray diffractometry method showed that in all the samples under study, regardless of the content of stabilizing impurities, there are not one, but two phases of the tetragonal modification of zirconia (Fig. 3) with different levels of tetragonality.

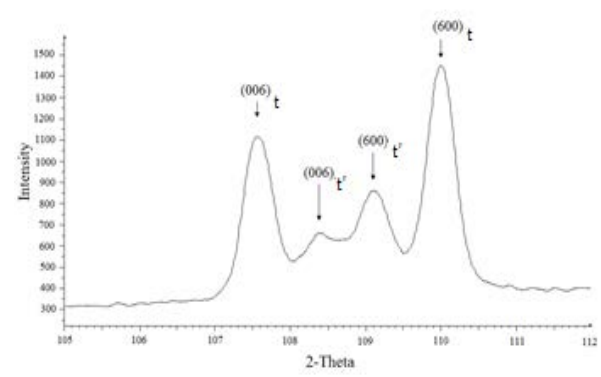

Fig. 3. Section of the diffraction pattern from the surface of the PSZ crystal, in the area of 006 and 600 reflections

Both phases have a slightly distorted fluorite structure and differ in the ratio of the cell parameters. For one tetragonal phase $(\mathrm{t})$, the c/a ratio was 1.014-1.015, and for the other tetragonal phase $\left(t^{\prime}\right)$, the c/a ratio differed little from 1 and amounted to 1.006-1.007. The $t^{\prime}$ phase is "nontransformable", in contrast to the $t$ phase, which undergoes a martensitic 
transition to a monoclinic form under the effect of mechanical stresses. Table 2 shows the data on the phase analysis with method of X-ray diffractometry of samples of zirconia crystals stabilized with concentrations of $\mathrm{Y}_{2} \mathrm{O}_{3}$ of 2.8 and $3.7 \mathrm{~mol} . \%$.

Table 2. Phase composition and parameters of lattice of $\mathrm{ZrO}_{2}$ depending on the content of the $\mathrm{Y}_{2} \mathrm{O}_{3}$ stabilizing impurity

\begin{tabular}{|l|l|l|l|l|}
\hline $\begin{array}{l}\text { Concentration of } \\
\mathrm{Y}_{2} \mathrm{O}_{3}\end{array}$ & Phase composition & $\mathrm{c}, \mathrm{nm}$ & $\mathrm{a}, \mathrm{nm}$ & $\mathrm{c} / \mathrm{a}$ \\
\hline $2.8 \mathrm{~mol} \%$ & $\mathrm{t}$ - phase & $0.5176 \pm 5 \cdot 10^{-5}$ & $0.5100 \pm 5 \cdot 10^{-5}$ & 1.015 \\
& $\mathrm{t}$ - phase & $0.5120 \pm 5 \cdot 10^{-5}$ & $0.5088 \pm 5 \cdot 10^{-5}$ & 1.006 \\
\hline 3.7 mol.\% & $\mathrm{t}$ - phase & $0.5171 \pm 5 \cdot 10^{-5}$ & $0.5099 \pm 5 \cdot 10^{-5}$ & 1.014 \\
& $\mathrm{t}$ - phase & $0.5123 \pm 5 \cdot 10^{-5}$ & $0.5089 \pm 5 \cdot 10^{-5}$ & 1.007 \\
\hline
\end{tabular}

Studies of PSZ crystals using method of transmission electronic microscopy showed that the samples have a developed twinning structure, formed during a cubic-tetragonal phase transition, which occurs during crystal growth, and the electron diffraction patterns contain reflections of the (110) type, which are forbidden in the cubic lattice and allowed in the tetragonal one, which is a confirmation of the results of phase analysis (Fig. 4).

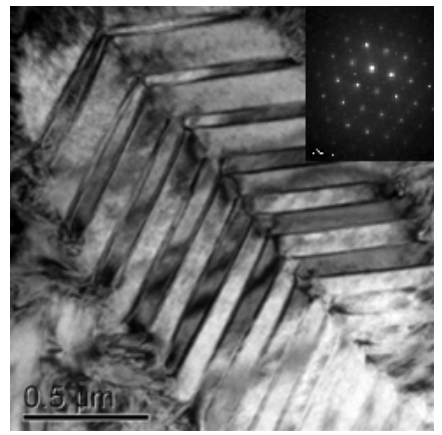

Fig. 4. Bright-field image of the twinned structure and the electron microdiffraction pattern typical for samples of PSZ crystals

Fig. 5. shows typical curves of indentation of a PSZ crystal sample under loading from 1 to $10 \mathrm{~N}$. It was experimentally established that no cracks were formed within the entire studied range of loads, which indicates a high crack resistance of crystals based on zirconia.

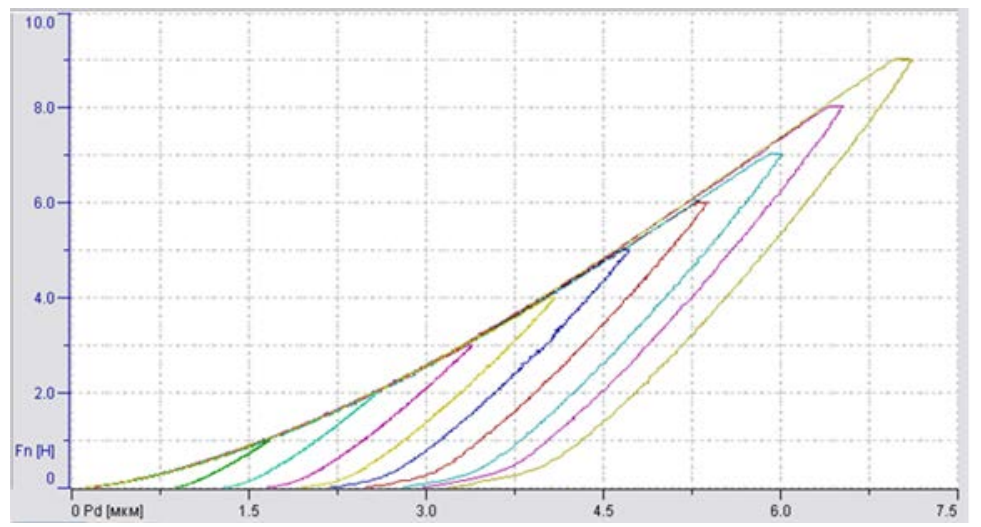

Fig. 5. Typical curves of indentation of a PSZ crystal sample under loading from 1 to $10 \mathrm{~N}$

Table 3 shows the test results of a batch of non-oriented PSZ crystals having a threecomponent composition of a stabilizing additive. The values of the Vickers microhardness 
(HV), the elastic modulus (E), the total work performed during the introduction of the Vickers pyramid $(\mathrm{W})$, the work of plastic deformation $\left(\mathrm{W}_{\mathrm{p}}\right)$, the coefficient of irreversible deformations, which includes the work of plastic deformation and energy loss during the formation of microcracks $\left(\mathrm{K}_{\mathrm{p}}\right)$

Table 3. Test results of samples of non-oriented PSZ crystals at a load of $3 \mathrm{~N}$ (three-component composition)

\begin{tabular}{|c|l|c|c|c|c|c|}
\hline No. & \multicolumn{1}{|c|}{ Composition } & $\mathrm{HV}$, & $\begin{array}{c}\mathrm{E}_{\mathrm{it}}, \\
(\mathrm{Hpa})\end{array}$ & $\mathrm{W}(\mu \mathrm{J})$ & $\begin{array}{c}\mathrm{W}_{\mathrm{p}} \\
(\mu \mathrm{J})\end{array}$ & $\mathrm{K}_{\mathrm{p}}$ \\
\hline 1 & $\mathrm{ZrO}_{2}+2,141 \% \mathrm{Y}_{2} \mathrm{O}_{3}+0,436$ & 1462 & 200 & 3,90 & 2,17 & 0,55 \\
& $\% \mathrm{CeO}_{2}+0,223 \% \mathrm{Nd}_{2} \mathrm{O}_{3}$ & 1403 & 199 & 3,95 & 2,19 & 0,55 \\
& & 1428 & 200 & 3,98 & 2,22 & 0,55 \\
\hline 2 & $\mathrm{ZrO}_{2}+2,036 \mathrm{M}_{2} \mathrm{Y}_{2} \mathrm{O}_{3}+0,653$ & 1422 & 162 & 4,22 & 2,12 & 0,50 \\
& $\% \mathrm{CeO}_{2}+0,111 \% \mathrm{Nd}_{2} \mathrm{O}_{3}$ & 1428 & 163 & 4,13 & 2,08 & 0,50 \\
& & 1436 & 163 & 4,15 & 2,09 & 0,50 \\
\hline 3 & $\mathrm{ZrO}_{2}+2,5 \% \mathrm{Y}_{2} \mathrm{O}_{3}+0,17 \%$ & 1452 & 190 & 3,98 & 2,13 & 0,53 \\
& $\mathrm{CeO}_{2}+0,13 \% \mathrm{Nd}_{2} \mathrm{O}_{3}$ & 1424 & 190 & 3,95 & 2,14 & 0,54 \\
& & 1446 & 188 & 3,97 & 2,14 & 0,53 \\
\hline 4 & $\mathrm{ZrO}_{2}+2,5 \% \mathrm{Y}_{2} \mathrm{O}_{3}+0,2 \%$ & 1552 & 196 & 3,84 & 1,98 & 0,51 \\
& $\mathrm{CeO}_{2}+0,1 \% \mathrm{Nd}_{2} \mathrm{O}_{3}$ & 1553 & 194 & 3,84 & 1,97 & 0,51 \\
& & 1592 & 194 & 3,86 & 1,99 & 0,51 \\
\hline 5 & $\mathrm{ZrO}_{2}+2,5 \% \mathrm{Y}_{2} \mathrm{O}_{3}+0,256 \%$ & 1497 & 199 & 3,93 & 2,12 & 0,54 \\
& $\mathrm{CeO}_{2}+0,044 \% \mathrm{Nd}_{2} \mathrm{O}_{3}$ & 1764 & 215 & 3,91 & 2,11 & 0,53 \\
& & 1494 & 197 & 3,91 & 2,12 & 0,54 \\
\hline 6 & $\mathrm{ZrO}_{2}+2,141 \% \mathrm{Y}_{2} \mathrm{O}_{3}+0,436$ & 1438 & 200 & 3,93 & 2,12 & 0,54 \\
& $\% \mathrm{CeO}_{2}+0,223 \% \mathrm{Nd}_{2} \mathrm{O}_{3}$ & 1460 & 198 & 3,90 & 2,14 & 0,54 \\
& & 1448 & 200 & 3,90 & 2,13 & 0,54 \\
\hline
\end{tabular}

In this batch of six studied unoriented samples with a three-component composition of the stabilizing additive, with regard to the best microhardness indicators, it is possible to distinguish the following subgroup: for samples Nos. 3-5 (Table 3) at a constant 2.5 mol.\% $\mathrm{Y}_{2} \mathrm{O}_{3}$ with an increase in mol.\% $\mathrm{CeO}_{2}(0.17$ mol.\%; $0.2 \mathrm{~mol} . \% ; 0.256$ mol.\%) and a corresponding decrease in mol.\% $\mathrm{Nd}_{2} \mathrm{O}_{3}(0.13 \mathrm{~mol} . \% ; 0.1 \mathrm{~mol} . \%$; $0.044 \mathrm{~mol} . \%)$ there is a slight increase in microhardness and Young's modulus is observed. Samples Nos. 3-5 have almost identical microhardness values. For samples 2 and 6 , the following can be noted: with an increase in mol. $\% \mathrm{Y}_{2} \mathrm{O}_{3}$ (from $2.031 \mathrm{~mol} \%$ to $2.036 \mathrm{~mol} \%$ ) and $\mathrm{mol} . \% \mathrm{CeO}_{2}$ (from $0.435 \mathrm{~mol} . \%$ to $0.653 \mathrm{~mol} . \%$ ) and a corresponding decrease in $\mathrm{mol} . \% \mathrm{Nd}_{2} \mathrm{O}_{3}$ (from 0.334 mol.\% to $0.111 \mathrm{~mol} \%$ ), a decrease in microhardness is observed. This trend can be traced when comparing samples No. 6 and No. 1. Among samples No. 1, No. 2, No. 6 (Table 3), the best values of microhardness and elastic modulus have an unoriented PSZ crystal No. 6 with composition of $\mathrm{ZrO}_{2}-2.031$ mol. $\% \mathrm{Y}_{2} \mathrm{O}_{3}+0.435 \mathrm{~mol} . \% \mathrm{CeO}_{2}+0.334 \mathrm{~mol} . \% \mathrm{Nd}_{2} \mathrm{O}_{3}$.

As can be seen from the analysis of the data given in Table 3 No. 4, PSZ crystals No. 4 with composition of $\mathrm{ZrO}_{2}-2.5$ mol.\% $\mathrm{Y}_{2} \mathrm{O}_{3}+0.2 \mathrm{~mol} . \% \mathrm{CeO}_{2}+0.1 \mathrm{~mol} . \% \mathrm{Nd}_{2} \mathrm{O}_{3}$; No. 5 with composition of $\mathrm{ZrO}_{2}-2.5 \mathrm{~mol} . \% \mathrm{Y}_{2} \mathrm{O}_{3}+0.256$ mol.\% $\mathrm{CeO}_{2}+0.044$ mol.\% $\mathrm{Nd}_{2} \mathrm{O}_{3}$, have the highest values of microhardness and elastic modulus. Sample No. 1 with the composition of $\mathrm{ZrO}_{2}-2.141$ mol.\% $\mathrm{Y}_{2} \mathrm{O}_{3}+0.436$ mol. $\% \mathrm{CeO}_{2}+0.223$ mol.\% $\mathrm{Nd}_{2} \mathrm{O}_{3}$ has the lowest microhardness values. It was established that the best parameters with regard to the plasticity criterion (coefficient of irreversible losses) also have unoriented crystals of the following compositions: No. 5 of $\mathrm{ZrO}_{2}-2.5$ mol.\% $\mathrm{Y}_{2} \mathrm{O}_{3}+0.256 \mathrm{~mol} . \% \mathrm{CeO}_{2}+0.044$ mol.\% $\mathrm{Nd}_{2} \mathrm{O}_{3}$. 


\section{Summary}

In terms of the combination of mechanical properties, nanostructured zirconia crystals are promising for replacing sapphires in the axle bearings of precision mechanics instruments, both in terms of performance properties and manufacturability.

As a result of the tests, all thrust bearings showed high crack resistance. However, it is possible to note the chipping on the sphere, and traces of oil burns. Probably, the presence of chipping indicates either insufficient material viscosity or anisotropy of crack toughness in PSZ crystals, which in the absence of orientation during the manufacture of a bearing can give a random version of the viscosity value.

Taking into account that the tested variants of single crystals were not oriented and fully studied, but were selected according to tribological characteristics, there is a high probability that when choosing the optimal composition in conjunction with the optimal crystal orientation during the manufacture of the bearing, the operational performance of the material can be significantly increased. Thus, it is possible to obtain a new material that meets the increased requirements of newly developed bearing pairs.

The work was supported by research grants No. 18-13-00397 of the Russian Science Foundation.

\section{References}

1. I.P. Kaur, V. Kakkar, P.K. Deol, et al. Issues and concerns in nanotech product development and its commercialization. J Control Release, 193, pp. 51-62, (2014)

2. Y. Zhu, H. Qu, M. Luo, C. He, J. Qu, Dry friction and wear properties of several hard coating combinations. Wear, 456-457, article 203352, (2020)

3. F. Schwack, N. Bader, J. Leckner, C. Demaille, G. Poll, A study of grease lubricants under wind turbine pitch bearing conditions. Wear, 454-455, article 203335, (2020)

4. X. Liu, N. Umehara, T. Tokoroyama, M. Murashima. Tribological properties of ta-CNx coating sliding against steel and sapphire in unlubricated condition. Tribology International, 131, 102-111, (2019)

5. C.A.L.L. Fonseca, I.F. Santos, H.I. Weber. Experimental comparison of the nonlinear dynamic behavior of a rigid rotor interacting with two types of different radial backup bearings: Ball \& pinned. Tribology International, 119, pp. 250-261, (2018).

6. M. Arghir, O. Benchekroun. A simplified structural model of bump-type foil bearings based on contact mechanics including gaps and friction. Tribology International, 134, pp. 129-144, (2019)

7. A. Chasalevris, F. Dohnal. Improving stability and operation of turbine rotors using adjustable journal bearings. Tribology International, 104, pp. 369-382, (2016)

8. V.V. Alisin, M.A. Borik, A.V. Kulebyakin, E.E. Lomonova, V.A. Myzina, O.A. Nelyubova, N.Yu. Tabachkova, O.N. Churlyaeva, Mechanical properties of partially stabilized zirconia crystals studied by kinetic microindentation. Inorganic Materials, 51, 6, pp 548-552, (2015)

9. M.A. Borik., M.A. Vishnyakova, V.P. Voitsitskii, A.V. Kulebyakin, E.E. Lomonova, V.A. Myzina, V.V. Osiko, V.A. Panov. Preparation and properties of Y2O3 partially stabilized $\mathrm{ZrO} 2$ crystals. Inorganic Materials, 43, 11, pp. 1223-1229, (2007)

10. D.R. Belichko, T.E. Konstantinova, A.V. Maletsky, N. Cornei, Influence of hafnium oxide on the structure and properties of powders and ceramics of the YSZ-HfO2 composition, Ceramics International. (to be published) 